\title{
Erratum to: Multiplex PCR Assay for the Detection of Five Putative Virulence Genes Encoded in Verotoxigenic Escherichia coli Plasmids
}

\author{
A. V. Bustamante - A. M. Sanso - P. M. A. Lucchesi • \\ A. E. Parma
}

Published online: 13 May 2011

(C) Springer Science+Business Media, LLC 2011

\section{Erratum to: Curr Microbiol (2011) 62:1411-1415 \\ DOI 10.1007/s00284-011-9877-5}

The original version of this article unfortunately contained two omissions. The lacking affiliation and the acknowledgements are presented here.

\section{Acknowledgments}

This work was supported by grants from the Consejo Nacional de Investigaciones Científicas y Técnicas (CONICET), Comisión de Investigaciones Científicas-Gobierno Pcia. Buenos Aires (CIC), FONCYT and SECAT-UNICEN.

The online version of the original article can be found under doi:10.1007/s00284-011-9877-5.

A. V. Bustamante $(\square) \cdot$ A. M. Sanso .

P. M. A. Lucchesi - A. E. Parma

Laboratorio de Inmunoquímica y Biotecnología, Facultad de Ciencias Veterinarias, Universidad Nacional del Centro de la Pcia. de Buenos Aires, Paraje Arroyo seco s/ nº, CP 7000 Tandil, Provincia de Buenos Aires, Argentina

e-mail: avbustaman@vet.unicen.edu.ar

A. V. Bustamante - A. M. Sanso - P. M. A. Lucchesi Comisión Nacional de Investigaciones Científicas y Técnicas (CONICET), Buenos Aires, Argentina 